\title{
ADUBAÇÃO NITROGENADA NO PERFILHAMENTO DA AVEIA-PRETA EM DUAS CONDIÇÕES DE FERTILIDADE DO SOLO ${ }^{1}$
}

\author{
JOÃO NAKAGAWA², CLÁUDIO CAVARIANI ${ }^{3}$ e JOSÉ RICARDO MACHADO ${ }^{4}$
}

\begin{abstract}
RESUMO - Para testar o efeito de seis doses de $\mathrm{N}(0,20,30,40,50$ e $60 \mathrm{~kg} / \mathrm{ha})$ aplicadas em cobertura, no final do perfilhamento, sobre a produção e a qualidade das sementes de Avena strigosa Schreber cv. Comum, foi conduzido um trabalho, em condições de campo, em Terra Roxa Estruturada distrófica, textura argilosa, em duas glebas com diferentes condições de fertilidade de solo. A gleba de menor fertilidade (pousio) apresentava saturação de bases (V) de 35\% e a de maior fertilidade (cultivo com batata), 49\%; nesta aplicou-se calcário para elevar a V para 70\%. Na semeadura, foram aplicados 20, 80 e $40 \mathrm{~kg} /$ ha de $\mathrm{N}_{2} \mathrm{P}_{2} \mathrm{O}_{5}$ e K $\mathrm{K}_{2} \mathrm{O}$, respectivamente. A adubação nitrogenada em cobertura não afetou nem os componentes da produção, nem a produtividade, nem a germinação das sementes, nos dois experimentos. Em condições de maior fertilidade do solo, a dose de $60 \mathrm{~kg} / \mathrm{ha}$ de $\mathrm{N}$ provocou aumento no acamamento das plantas e diminuição do peso hectolítrico. Em condições de menor fertilidade de solo, a adubação nitrogenada ocasionou aumentos na produção de massa vegetativa seca da parte aérea, e quando na dose de $60 \mathrm{~kg} / \mathrm{ha}$, aumentou o teor de proteína das sementes.
\end{abstract}

Termos para indexação: Avena strigosa, semente, nitrogênio, acamamento, matéria seca, partes aéreas, peso.

\section{NITROGEN FERTILIZATION AT TILLERING OF BLACK-OAT IN TWO SOIL FERTILITY CONDITIONS}

\begin{abstract}
The objective of this work was to study the effect of six doses of $\mathrm{N}(0,20,30,40,50$ and $60 \mathrm{~kg} / \mathrm{ha}$ ) applied at the end of tillering stage, on yield and seed quality of Avena strigosa Schreber cv. Comum, under two conditions of soil fertility. The experiments were carried out under field conditions on a Ultisol (distrophic Terra Roxa Estruturada), in Botucatu, SP, Brazil. The soil with less fertility (fallow land) presented $35 \%$ of soil base saturation. The soil with high fertility (previously with potato crop) had $49 \%$ of soil base saturation and received lime to increase it to $70 \%$. All plots received basal fertilization of 20,80 and $40 \mathrm{~kg} /$ ha of $\mathrm{N}_{2} \mathrm{P}_{2} \mathrm{O}_{5}$ and $\mathrm{K}_{2} \mathrm{O}$. The yield and seed germination were not affected by $\mathrm{N}$ top dressing under both soil conditions. Under high fertility soil, the $60 \mathrm{~kg} / \mathrm{ha}$ of $\mathrm{N}$ dose gave rise to the lodging and the decrease of the hectolitric weight of the seeds. Under less fertility soil, the $\mathrm{N}$ fertilization increased the dry weight of aerial part and improved the seed protein content at the highest dose of $\mathrm{N}$.
\end{abstract}

Index terms: Avena strigosa, seed, nitrogen, lodging, dry matter, aerial parts, weight.

\section{INTRODUÇÃO}

A aveia-preta (Avena strigosa Schreber) é uma gramínea que tem sido estudada e empregada na Região Sul do Brasil e no Estado de São Paulo, como

\footnotetext{
${ }^{1}$ Aceito para publicação em 2 de março de 2000.

${ }^{2}$ Eng. Agrôn., Prof. Titular, Faculdade de Ciências Agronômicas (FCA), Universidade Estadual Paulista (UNESP), Caixa Postal 237, CEP18603-970 Botucatu, SP. Bolsista do CNPq. E-mail: secdamv@fca.unesp.br

${ }^{3}$ Eng. Agrôn., Dr., Prof. Assistente, FCA, UNESP-Botucatu.

${ }^{4}$ Eng. Agrôn., Prof. Adjunto, FCA, UNESP-Botucatu.
}

forrageira (Salerno \& Vetterle, 1984; Fontaneli \& Piovezan, 1991; Godoy \& Batista, 1992; Reis et al., 1992) e material para adubação verde de inverno, com bons resultados (Derpsch et al., 1985; Trani et al., 1989; Santos, 1991). Por ser uma cultura relativamente recente no país, há poucos trabalhos de pesquisa com a espécie, principalmente com relação à produção e à qualidade das sementes.

A adubação nitrogenada, além do efeito na produtividade, pode influir no teor de proteína das sementes (Ohm, 1976; Rattunde \& Frey, 1986). Em trabalhos feitos com trigo, o teor de proteína nas sementes tem-se correlacionado positivamente com o 
vigor delas (Carvalho \& Nakagawa, 1988). Todavia, nem sempre foram obtidos efeitos de doses de $\mathrm{N}$ no teor de proteína ou na qualidade fisiológica das sementes de trigo (Vieira et al., 1986, 1995) ou de outros cereais (Maeda et al., 1979; Costa et al., 1983), em face das influências das técnicas de cultivo e das condições edáficas e climáticas nos resultados.

Em aveia-preta, as pesquisas com adubação nitrogenada, relacionando doses ou momentos de aplicação e a produção ou qualidade das sementes, são em pequeno número até o momento (Nakagawa et al., 1994, 1995, 1996), situação esta contrária à verificada em Avena sativa L. (Frey, 1959; Ohm, 1976; Brinkman \& Rho, 1984; Rattunde \& Frey, 1986; Marshall et al., 1987; Humphreys et al., 1994).

Nakagawa et al. (1994, 1995), estudando em aveiapreta doses e épocas de aplicação de N (na semeadura, no perfilhamento da planta e na emergência da panícula), verificaram a importância do fornecimento do elemento no perfilhamento, para a produção (Nakagawa et al., 1994, 1995) e a qualidade fisiológica das sementes (Nakagawa et al., 1995), com destaque ao tratamento que recebeu $20 \mathrm{~kg} / \mathrm{ha}$ na semeadura e $20 \mathrm{~kg} / \mathrm{ha}$ no perfilhamento.

Este trabalho objetivou verificar o efeito de doses de $\mathrm{N}$ aplicado no perfilhamento da planta sobre a produção e a qualidade das sementes de aveia-preta, em duas condições de fertilidade do solo.

\section{MATERIAL E MÉTODOS}

O trabalho constou de dois experimentos conduzidos com aveia-preta cv. Comum, em condições de campo, em solo Terra Roxa Estruturada distrófica, textura argilosa (Carvalho et al., 1983), pertencente à Fazenda Experimental Lageado (FEL) do Campus de Botucatu - UNESP. O experimento 1 foi instalado em local onde no ano anterior havia sido cultivada batata, e o experimento 2 , em área de pousio. Os resultados da análise do solo dos locais encontram-se na Tabela 1. Os dados referentes às precipitações pluviais, temperaturas máximas e mínimas diárias observadas no período do trabalho, no Posto Meteorológico da FEL, estão apresentados na Fig. 1.

Foram estudados os efeitos de seis doses de $\mathrm{N}(0,20$, $30,40,50$ e $60 \mathrm{~kg} / \mathrm{ha}$ ) aplicadas no final do perfilhamento das plantas, em cobertura, na forma de sulfato de amônio. $\mathrm{O}$ delineamento experimental empregado em cada experimento foi o de blocos ao acaso, com seis tratamentos e quatro repetições. As parcelas constaram de 12 linhas de $5 \mathrm{~m}$ de comprimento cada, com espaçamento entre linhas de $0,20 \mathrm{~m}$. Na colheita, foram desprezadas as linhas externas, bem como $0,50 \mathrm{~m}$ de cada extremidade das linhas centrais, perfazendo uma área útil de $8 \mathrm{~m}^{2}$.

Com base nos resultados de análise química de solo (Tabela 1), foram aplicadas $2,2 \mathrm{t} /$ ha de calcário dolomítico para elevar a saturação de bases para $70 \%$, com 30 dias de antecedência à semeadura, somente no experimento 1. Em ambos os experimentos foram aplicados abaixo do sulco de semeadura $20 \mathrm{~kg} / \mathrm{ha} \mathrm{de} \mathrm{N}, 80 \mathrm{~kg} / \mathrm{ha}$ de $\mathrm{P}_{2} \mathrm{O}_{5}$ e $40 \mathrm{~kg} / \mathrm{ha}$ de $\mathrm{K}_{2} \mathrm{O}$ nas formas de sulfato de amônio, superfosfato simples e cloreto de potássio, considerando os valores encontrados nas Instruções Técnicas para o Estado de São Paulo (Instituto Agronômico, 1986). As semeaduras foram realizadas manualmente, empregando-se 36 sementes viáveis por metro linear, em 9/5/95. O controle de plantas daninhas foi feito manualmente, quando necessário.

Por ocasião da colheita, realizada em 18/9/95, foram coletadas as plantas consecutivas de $0,5 \mathrm{~m}$ de linhas por parcela, determinando-se o número de plantas e a sua altura, o comprimento da panícula do colmo principal, o número de perfilhos por planta, a porcentagem de perfilhos úteis, o número de sementes por panícula do colmo principal, o número médio de sementes por panícula dos perfilhos, o peso de 1.000 sementes da panícula do colmo principal, o peso médio de 1.000 sementes das panículas dos perfilhos, a produção de sementes por planta e a contribuição porcentual dos perfilhos na produção de sementes por planta. Foi também feita uma avaliação da porcentagem de plantas acamadas, antes da colheita.

A produtividade das sementes e o peso da matéria seca da parte aérea sem as sementes foram calculados com base nos dados de produção coletados na área útil da parcela. Nesta determinou-se também o número de plantas $/ \mathrm{m}^{2}$ por parcela. Calculou-se o índice de colheita, empregando-se os dados da produção de sementes e da matéria seca da parte aérea das plantas de cada parcela.

Nas sementes foram determinados o peso hectolítrico, a pureza física e o peso de 1.000 sementes, com base nas Regras para Análise de Sementes (Brasil, 1992). A qualidade fisiológica das sementes foi avaliada pelo teste padrão de germinação e de testes de vigor ( $1^{a}$ contagem, envelhecimento rápido, condutividade elétrica, porcentagem e velocidade de emergência de plântulas no campo), empregando-se o método do trabalho anterior (Nakagawa et al., 1996).

Determinou-se o teor de proteína das sementes, utilizando-se o método de Kjeldahl (Association of Official Analytical Chemists, 1975).

Os parâmetros avaliados foram analisados estatisticamente, com base nas recomendações encontradas em Pimentel-Gomes (1966). 
TABELA 1. Resultados da análise química de solo dos locais dos experimentos 1 e 2 antes de sua instalação.

\begin{tabular}{|c|c|c|c|c|c|c|c|c|c|}
\hline Locais & $\begin{array}{l}\mathrm{pH} \mathrm{em} \\
\mathrm{CaCl}_{2}\end{array}$ & $\begin{array}{c}\mathrm{MO} \\
\left(\mathrm{g} / \mathrm{dm}^{3}\right)\end{array}$ & $\begin{array}{l}\text { P resina } \\
\left(\mathrm{mg} / \mathrm{dm}^{3}\right)\end{array}$ & $\mathrm{H}^{+}+\mathrm{Al}^{3+}$ & $\mathrm{K}^{+}$ & $\begin{array}{c}\mathrm{Ca}^{2+} \\
-\left(\mathrm{mmol}_{\mathrm{c}} / \mathrm{dm}^{3}\right)-\end{array}$ & $\mathrm{Mg}^{2+}$ & 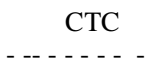 & $\begin{array}{c}\mathrm{V} \\
(\%)\end{array}$ \\
\hline Experimento 1 & 5,10 & 14,4 & 22,0 & 38 & 2,4 & 23,2 & 11,3 & 74,9 & 49 \\
\hline Experimento 2 & 4,51 & 17,1 & 10,7 & 45 & 2,3 & 14,7 & 6,8 & 68,8 & 35 \\
\hline
\end{tabular}

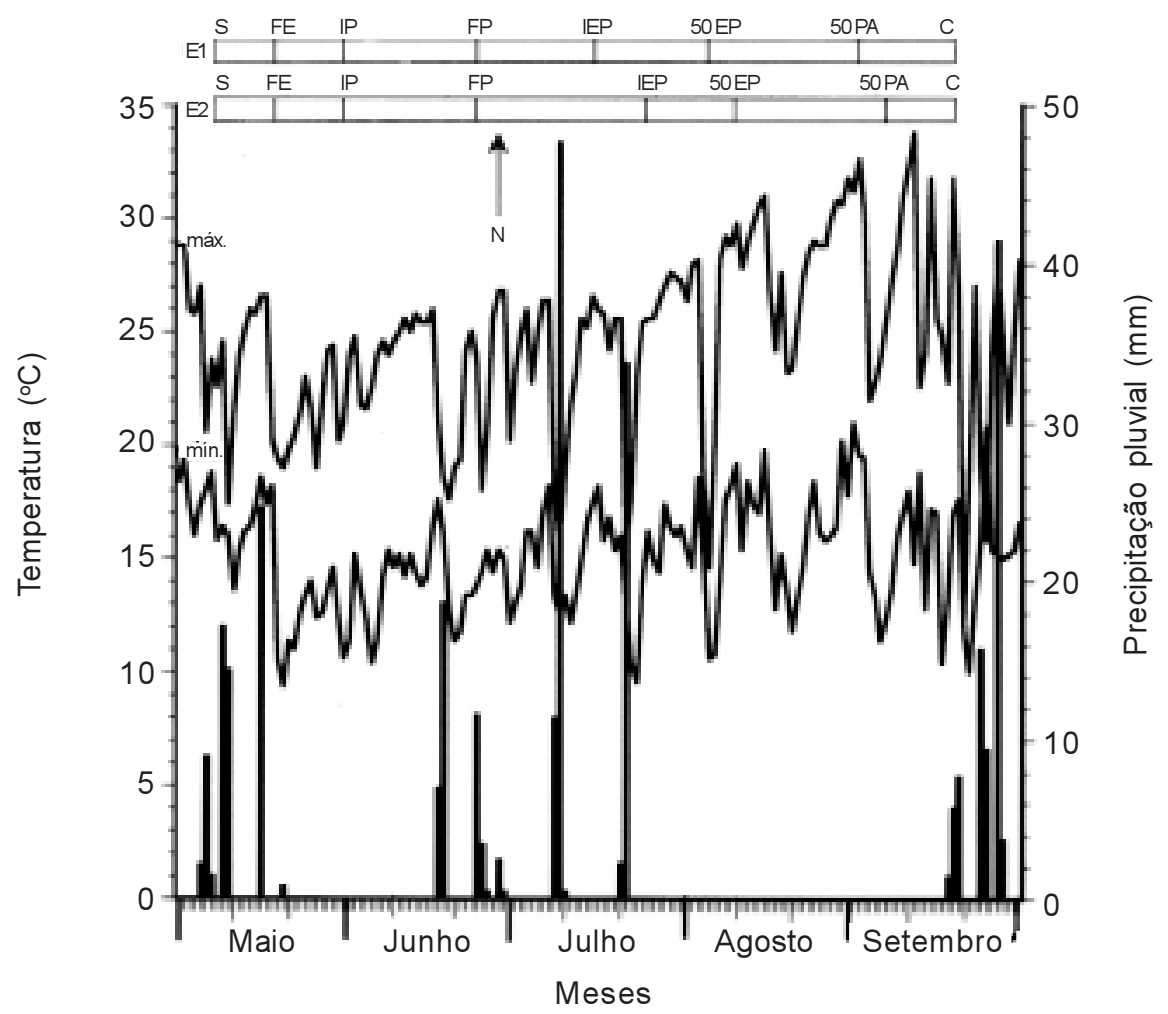

FIG. 1. Dados diários de temperaturas máxima e mínima e precipitação pluvial observados no período dos experimentos (E1 e E2). Principais estádios de desenvolvimento da aveia-preta $(S=$ semeadura; $F E=$ final de emergência de plântulas; IP = início do perfilhamento; FP = final do perfilhamento; IEP = início de emergência de panícula; $50 \mathrm{EP}=\mathbf{5 0} \%$ de emergência de panículas; 50PA $=50 \%$ de panículas amarelas; $C=$ colheitas; $\uparrow=$ aplicação de $N$ ).

\section{RESULTADOS E DISCUSSÃo}

\section{Experimento 1}

Pela Fig. 1, onde está representada ocorrência dos principais estádios de desenvolvimento (média dos tratamentos) das plantas de aveia-preta dos ex- perimentos $1 \mathrm{e} 2$, pode-se constatar que, em face das condições climáticas favoráveis, a germinação e a emergência das plântulas foram rápida e uniforme. Após o início do perfilhamento houve um período sem chuvas, porém a seguir estas voltaram a ocorrer em quantidade para o perfilhamento se completar, e possibilitar a adubação em cobertura com N, em con- 
dições favoráveis de umidade do solo. Na fase de desenvolvimento e maturação das sementes ocorreu outro período sem chuvas, que aparentemente não interferiu nos estádios das plantas. As diferenças verificadas entre os dois experimentos nos estádios de emergência e de maturação de panículas devem estar mais relacionadas às condições químicas dos solos dos locais dos experimentos (Tabela 1) do que às condições climáticas reinantes. Assim, observa-se que no experimento 1 sob condições de melhor fertilidade de solo houve antecipação da fase reprodutiva da planta, à semelhança do observado por Brown et al. (1961), em aveia-branca.

Pelos dados da Tabela 2, verifica-se que houve diferença na população final de plantas entre alguns tratamentos; todavia, o efeito prejudicial da adubação nitrogenada na dose de $20 \mathrm{~kg} / \mathrm{ha}$, em relação às doses 0 e $30 \mathrm{~kg} / \mathrm{ha}$, fica difícil de ser interpretado, considerando-se a época em que foi feita a aplicação. Esta diferença, entretanto, não alterou o comportamento das outras características analisadas.

A altura da planta não foi afetada pelos tratamentos (Tabela 2). Nakagawa et al. $(1994,1995)$ haviam verificado tendência de aumento da altura das plantas, quando a dose de $\mathrm{N}$ foi aumentada de 0 para 20 e desta para $40 \mathrm{~kg} / \mathrm{ha}$, aplicados no perfilhamento. Neste trabalho, as plantas desenvolveram-se bem em todos os tratamentos em virtude das condições climáticas favoráveis na fase de crescimento (Fig. 1).
O número de perfilhos por planta e a porcentagem de perfilhos úteis (Tabela 2) não foram influenciados pelas doses de N, concordando com os resultados de Nakagawa et al. $(1994,1995)$. Isto mostra que, por ocasião da cobertura realizada com $\mathrm{N}$, todas as plantas já haviam paralisado o seu perfilhamento e a adubação não provocou sua continuidade.

À semelhança da altura da planta, o comprimento da panícula do colmo principal não diferiu entre os tratamentos. Nakagawa et al. $(1994,1995)$, entretanto, obtiveram aumentos significativos no comprimento da panícula, em função das doses de $\mathrm{N}$ fornecidas no perfilhamento. Deve-se ressaltar, todavia, que os valores de comprimento da panícula obtidos no presente trabalho foram superiores aos do trabalho referido, provavelmente em razão das boas condições de solo (Tabela 1).

O número de sementes por panícula do colmo principal e o número médio de sementes por panícula dos perfilhos foram semelhantes, estatisticamente, em todas as doses de $\mathrm{N}$, resultados, estes, concordantes com os obtidos por Nakagawa et al. (1994, 1995). O número de sementes por panícula do colmo principal foi quase duas vezes superior ao das panículas dos perfilhos.

Os pesos de 1.000 sementes da panícula do colmo principal e das panículas dos perfilhos não foram influenciados pelos tratamentos (Tabela 3), apresentando valores bem próximos entre si.

TABELA 2. Dados médios de número de plantas por $\mathrm{m}^{2}$, altura da planta $(\mathrm{cm})$, número de perfilhos por planta, porcentagem de perfilhos úteis, comprimento da panícula do colmo principal $(\mathrm{cm})$, número de sementes por panícula do colmo principal e número médio de sementes por panícula dos perfilhos obtidos nos tratamentos com doses de $\mathbf{N}$ aplicadas em cobertura no perfilhamento das plantas de aveia-preta. Experimento $\mathbf{1}^{1}$.

\begin{tabular}{|c|c|c|c|c|c|c|c|}
\hline $\begin{array}{c}\text { Doses de N } \\
(\mathrm{kg} / \mathrm{ha})\end{array}$ & $\begin{array}{c}\text { Plantas por } \\
\mathrm{m}^{2} \\
\left(\mathrm{n}^{\mathrm{o}}\right)\end{array}$ & $\begin{array}{l}\text { Altura da } \\
\text { planta } \\
(\mathrm{cm})\end{array}$ & $\begin{array}{l}\text { Perfilhos por } \\
\text { planta } \\
\left(\mathrm{n}^{\circ}\right)\end{array}$ & $\begin{array}{l}\text { Perfilhos } \\
\text { úteis } \\
(\%)\end{array}$ & $\begin{array}{l}\text { Comprimento da } \\
\text { panícula do colmo } \\
\text { principal } \\
(\mathrm{cm})\end{array}$ & $\begin{array}{c}\text { Sementes por } \\
\text { panícula do colmo } \\
\text { principal } \\
\left(\mathrm{n}^{\circ}\right)\end{array}$ & $\begin{array}{l}\text { Sementes por } \\
\text { panícula dos } \\
\text { perfilhos } \\
\left(\mathrm{n}^{\circ}\right)\end{array}$ \\
\hline 0 & $95,0 \mathrm{a}$ & $163,4 a$ & $6,08 \mathrm{a}$ & $77,28 \mathrm{a}$ & $23,9 a$ & $57,4 a$ & $28,9 a$ \\
\hline 20 & $82,5 b$ & $163,2 \mathrm{a}$ & $6,13 a$ & $69,96 a$ & $23,7 \mathrm{a}$ & $60,8 \mathrm{a}$ & $33,2 \mathrm{a}$ \\
\hline 30 & $95,0 \mathrm{a}$ & $158,6 \mathrm{a}$ & $5,61 \mathrm{a}$ & $69,65 a$ & $23,0 \mathrm{a}$ & $57,4 \mathrm{a}$ & $30,9 a$ \\
\hline 40 & $92,5 \mathrm{ab}$ & $163,4 \mathrm{a}$ & $6,02 \mathrm{a}$ & $76,75 a$ & $23,8 \mathrm{a}$ & $52,6 a$ & $32,7 \mathrm{a}$ \\
\hline 50 & $92,5 \mathrm{ab}$ & $160,0 \mathrm{a}$ & $6,07 \mathrm{a}$ & $70,51 \mathrm{a}$ & $24,0 \mathrm{a}$ & $62,1 \mathrm{a}$ & $31,1 \mathrm{a}$ \\
\hline 60 & $87,5 \mathrm{ab}$ & $155,9 \mathrm{a}$ & $5,72 \mathrm{a}$ & $79,16 \mathrm{a}$ & $23,0 \mathrm{a}$ & $54,6 \mathrm{a}$ & $29,6 \mathrm{a}$ \\
\hline C.V. $(\%)$ & 3,01 & 3,34 & 5,96 & 8,72 & 6,44 & 9,73 & 9,37 \\
\hline
\end{tabular}

${ }^{1}$ Médias na coluna seguidas da mesma letra não diferem significativamente entre si a $5 \%$ de probabilidade pelo teste Tukey. 


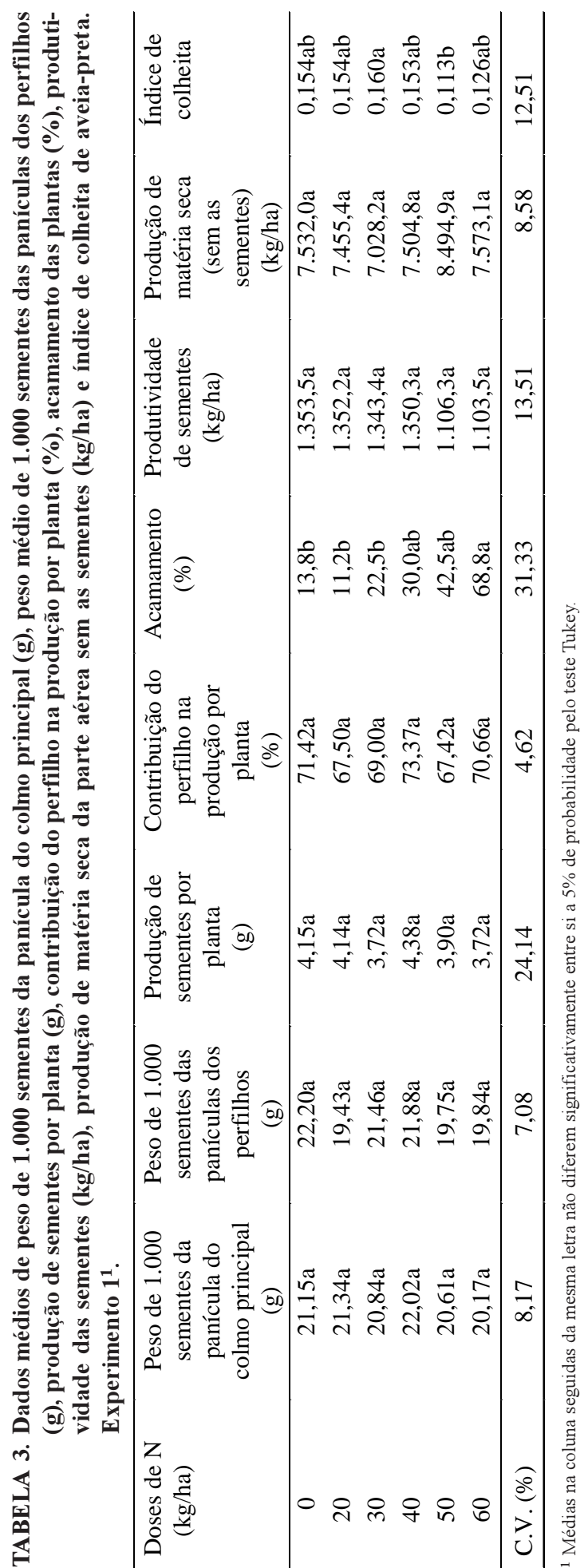

A produção de sementes por planta (Tabela 3) não mostrou diferença significativa entre os tratamentos, pelo fato de os componentes de produção por planta (Tabelas 2 e 3 ) não terem também diferido entre si, o que concorda com os resultados de Nakagawa et al. (1995). Analisando-se a contribuição dos perfilhos para a produção de sementes por planta, observa-se que não houve diferença significativa entre as doses de $\mathrm{N}$ (Tabela 3 ).

Tendo em vista as condições ambientais (Tabela 1 e Fig. 1) favoráveis ao desenvolvimento das plantas (Tabelas 2 e 3), verificou-se, neste experimento, a ocorrência de acamamento das plantas imediatamente após a emergência das panículas, notadamente nas parcelas com as doses maiores de $\mathrm{N}(40,50 \mathrm{e}$ $60 \mathrm{~kg} / \mathrm{ha}$ ). Na avaliação realizada por ocasião da colheita (Tabela 3), constatou-se que o acamamento provocado pela dose de $60 \mathrm{~kg} / \mathrm{ha}$ foi significativamente superior ao acamamento provocado pelas doses de 0,20 e $30 \mathrm{~kg} / \mathrm{ha}$, enquanto os provocados pelas doses de 40 e $50 \mathrm{~kg} / \mathrm{ha}$ colocaram-se em posição intermediária. É importante salientar que mesmo a testemunha (dose zero) apresentou acamamento acima de $10 \%$, provavelmente em razão do bom desenvolvimento das plantas.

A produtividade de sementes não foi afetada pelas doses de N (Tabela 3), à semelhança da produção por planta, apesar da diferença na população de plantas final (Tabela 2), que não chegou a afetar os resultados de produtividade. Embora a análise estatística não tenha detectado diferença significativa, observa-se que os tratamentos com 50 e $60 \mathrm{~kg} / \mathrm{ha}$ de $\mathrm{N}$, com as maiores porcentagens de acamamento, proporcionaram os menores valores de produtividade de sementes, em decorrência de prováveis perdas e dificuldades de colheita.

Ao se avaliar a produção de matéria seca da parte aérea, sem as sementes (Tabela 3), verifica-se que não houve diferença entre as doses de $\mathrm{N}$, à semelhança da produtividade de semente. Entretanto, o índice de colheita foi afetado pelos tratamentos, com melhor comportamento da dose de $30 \mathrm{~kg} / \mathrm{ha}$ de N, e com pior, o da dose de $50 \mathrm{~kg} / \mathrm{ha}$ de N (Tabela 3); estes não diferiram dos demais.

Por estes resultados, pode-se verificar que a produtividade de sementes foi elevada, quando comparada aos dos trabalhos anteriores (Nakagawa et al., 
1994, 1995), assim como a produção de matéria seca da parte vegetativa aérea; todavia, como as doses maiores de $\mathrm{N}(40,50$ e $60 \mathrm{~kg} / \mathrm{ha})$ ocasionaram acamamento das plantas já na fase de emissão das panículas, a produção potencial de sementes destes tratamentos deve ter sido prejudicada, associandose ainda às perdas de sementes ocorridas na colheita das plantas acamadas. Resultados semelhantes obtiveram Brinkman \& Rho (1984) em aveia-branca.

O teor de proteína das sementes (Tabela 4) não foi significativamente afetado pelas doses de N, embora as doses maiores tenham apresentado valores numéricos superiores. Ohm (1976) verificou aumento do teor de proteína nas sementes de aveia-branca com a aplicação de $\mathrm{N}$, porém o nível de resposta variou entre as cultivares.

O peso hectolítrico e a pureza física das sementes (Tabela 4) foram afetados pelas doses de N, com maiores valores para a dose de $20 \mathrm{~kg} / \mathrm{ha}$. Nas maiores doses observou-se queda nestas características físicas. Tais resultados podem estar relacionados ao acamamento sofrido pelas plantas na fase de maturação das sementes, pois com o acamamento nesta fase, a fotossíntese provavelmente foi prejudicada, e com isto menores quantidades de fotossintetizados foram translocados às panículas, obtendose então, nos tratamentos com mais plantas acamadas, maior número de sementes mal formadas e também chochas, que resultaram nos menores valores do peso hectolítrico e da porcentagem de pureza física.

O peso de 1.000 sementes, avaliado nas sementes puras, não mostrou diferença entre tratamentos, à semelhança do observado para peso de 1.000 sementes da panícula principal e dos perfilhos.

Ao avaliar-se a qualidade fisiológica das sementes, constatou-se que não houve efeito das doses de $\mathrm{N}$ na germinação das sementes e no vigor, pelos testes de primeira contagem, envelhecimento rápido, porcentagem e velocidade de emergência de plântulas. Entretanto, pelo teste de condutividade elétrica, verificou-se que com o aumento das doses de $\mathrm{N}$ até $40 \mathrm{~kg} /$ ha houve melhoria da qualidade, declinando a partir de então, decréscimo, este, que deve estar relacionado com o problema do acamamento. Este tratamento (40 kg/ha) foi também o que resultou nos maiores valores numéricos nos testes conduzidos

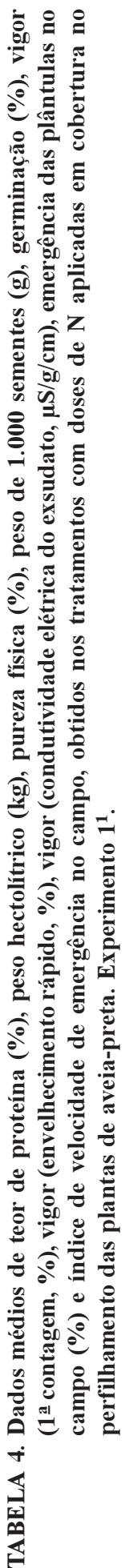

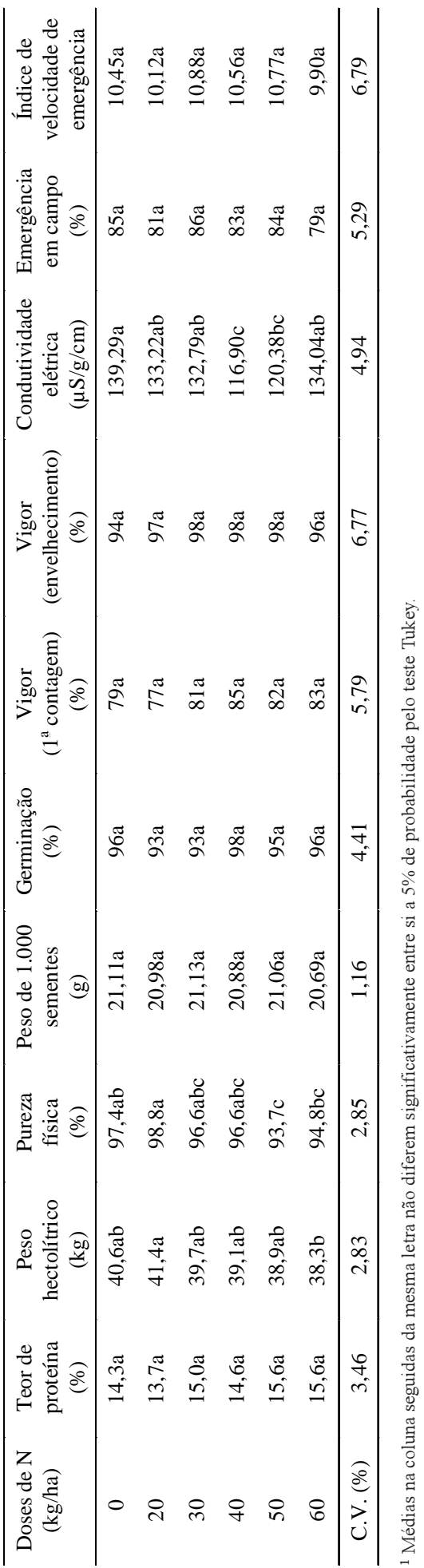


em laboratório, apesar de não diferir dos demais estatisticamente (Tabela 4). Nakagawa et al. (1995) encontraram diferença de qualidade fisiológica das sementes entre a testemunha e os tratamentos que receberam $\mathrm{N}$ no perfilhamento, apenas pelo teste de vigor de primeira contagem. É importante salientar que, no trabalho citado, o teste de condutividade elétrica não foi empregado.

\section{Experimento 2}

O desenvolvimento das plantas em seus estádios iniciais foram semelhantes nos dois experimentos em relação a todos os tratamentos (Fig. 1). Após o fim do perfilhamento, começaram a surgir diferenças visíveis de desenvolvimento entre os dois experimentos. Desta forma, no experimento 2, onde as condições químicas do solo devem ter sido menos favoráveis (Tabela 1), observou-se um atraso na emergência de panículas e conseqüentemente na maturação. Tal resultado poderia ser atribuído ao menor teor de P (Tabela 1), pois em arroz, quando há deficiência, observa-se o mesmo problema (Baba \& Iwata, 1967).

A população de plantas final deste experimento (Tabela 5) foi semelhante em todos os tratamentos, portanto não deve ter interferido nos resultados das demais características. Os valores encontrados foram semelhantes aos do experimento 1 (Tabela 2).

A altura das plantas (Tabela 5) não foi também afetada pelas doses de N, e atingiu um crescimento bem próximo ao das plantas do experimento 1 (Tabela 2), apesar das diferenças de fertilidade dos solos.

O número de perfilhos por planta apresentou diferença entre os tratamentos (Tabela 5), porém não ficou bem caracterizado o efeito das doses de N. A porcentagem de perfilhos úteis não foi afetada pelas doses de $\mathrm{N}$, à semelhança do verificado no experimento 1 .

O comprimento e o número de sementes por panícula do colmo principal, o número médio de sementes da panícula dos perfilhos (Tabela 5), o peso de 1.000 sementes da panícula do colmo principal e o peso de 1.000 sementes das panículas dos perfilhos (Tabela 6) não apresentaram diferenças significativas entre tratamentos. De maneira semelhante, a produção de sementes por planta e a contribuição dos perfilhos na produção por planta (Tabela 6) não foram afetados pelas doses de $\mathrm{N}$, por não terem os componentes da produção por planta apresentado diferenças entre tratamentos (Tabelas 5 e 6), o que concorda com os resultados do experimento 1 e com os de Nakagawa et al. (1995).

No experimento 2, verificou-se também o acamamento de plantas na fase final do ciclo, com a maior porcentagem de acamamento sendo observada na dose maior, seguida da testemunha (Tabela 6). Quanto a esta característica, houve uma variação muito grande entre as repetições, o que vem dificultar a interpretação do efeito das doses sobre o acamamento das plantas.

TABELA 5. Dados médios de número de plantas por $\mathrm{m}^{2}$, altura da planta $(\mathrm{cm})$, número de perfilhos por planta, porcentagem de perfilhos úteis, comprimento da panícula do colmo principal $(\mathrm{cm})$, número de sementes por panícula do colmo principal e número médio de sementes por panícula dos perfilhos obtidos nos tratamentos com doses de $\mathrm{N}$ aplicadas em cobertura no perfilhamento das plantas de aveia-preta. Experimento 21.

\begin{tabular}{cccccccc}
\hline $\begin{array}{c}\text { Doses de N } \\
(\mathrm{kg} / \mathrm{ha})\end{array}$ & $\begin{array}{c}\text { Plantas } \\
\text { por } \mathrm{m}^{2} \\
\left(\mathrm{n}^{\mathrm{o}}\right)\end{array}$ & $\begin{array}{c}\text { Altura da } \\
\text { planta } \\
(\mathrm{cm})\end{array}$ & $\begin{array}{c}\text { Perfilhos por } \\
\text { planta } \\
\left(\mathrm{n}^{\mathrm{o}}\right)\end{array}$ & $\begin{array}{c}\text { Perfilhos } \\
\text { úteis } \\
(\%)\end{array}$ & $\begin{array}{c}\text { Comprimento da } \\
\text { panícula do colmo } \\
\text { principal } \\
(\mathrm{cm})\end{array}$ & $\begin{array}{c}\text { Sementes por } \\
\text { panícula do colmo } \\
\text { principal } \\
\left(\mathrm{n}^{\mathrm{o}}\right)\end{array}$ & $\begin{array}{c}\text { Sementes por } \\
\text { panícula dos } \\
\text { perfilhos } \\
\left(\mathrm{n}^{\circ}\right)\end{array}$ \\
\hline 0 & $90,0 \mathrm{a}$ & $157,2 \mathrm{a}$ & $5,87 \mathrm{ab}$ & $69,64 \mathrm{a}$ & $22,1 \mathrm{a}$ & $50,6 \mathrm{a}$ & $28,7 \mathrm{a}$ \\
20 & $85,0 \mathrm{a}$ & $159,1 \mathrm{a}$ & $5,37 \mathrm{~b}$ & $65,33 \mathrm{a}$ & $22,4 \mathrm{a}$ & $53,4 \mathrm{a}$ & $26,6 \mathrm{a}$ \\
30 & $82,5 \mathrm{a}$ & $163,2 \mathrm{a}$ & $7,29 \mathrm{a}$ & $62,76 \mathrm{a}$ & $22,4 \mathrm{a}$ & $53,8 \mathrm{a}$ & $27,4 \mathrm{a}$ \\
40 & $92,5 \mathrm{a}$ & $155,6 \mathrm{a}$ & $6,03 \mathrm{ab}$ & $75,57 \mathrm{a}$ & $22,8 \mathrm{a}$ & $54,9 \mathrm{a}$ & $25,0 \mathrm{a}$ \\
50 & $95,0 \mathrm{a}$ & $158,6 \mathrm{a}$ & $5,79 \mathrm{ab}$ & $81,33 \mathrm{a}$ & $22,8 \mathrm{a}$ & $60,9 \mathrm{a}$ & $29,5 \mathrm{a}$ \\
60 & $87,5 \mathrm{a}$ & $159,8 \mathrm{a}$ & $6,10 \mathrm{ab}$ & $71,11 \mathrm{a}$ & $22,1 \mathrm{a}$ & $57,4 \mathrm{a}$ & $29,8 \mathrm{a}$ \\
\hline C.V. $(\%)$ & 4,93 & 5,58 & 6,32 & 12,01 & 6,80 & 6,74 & 9,03 \\
\hline
\end{tabular}

${ }^{1}$ Médias na coluna seguidas da mesma letra não diferem significativamente entre si a $5 \%$ de probabilidade pelo teste Tukey. 


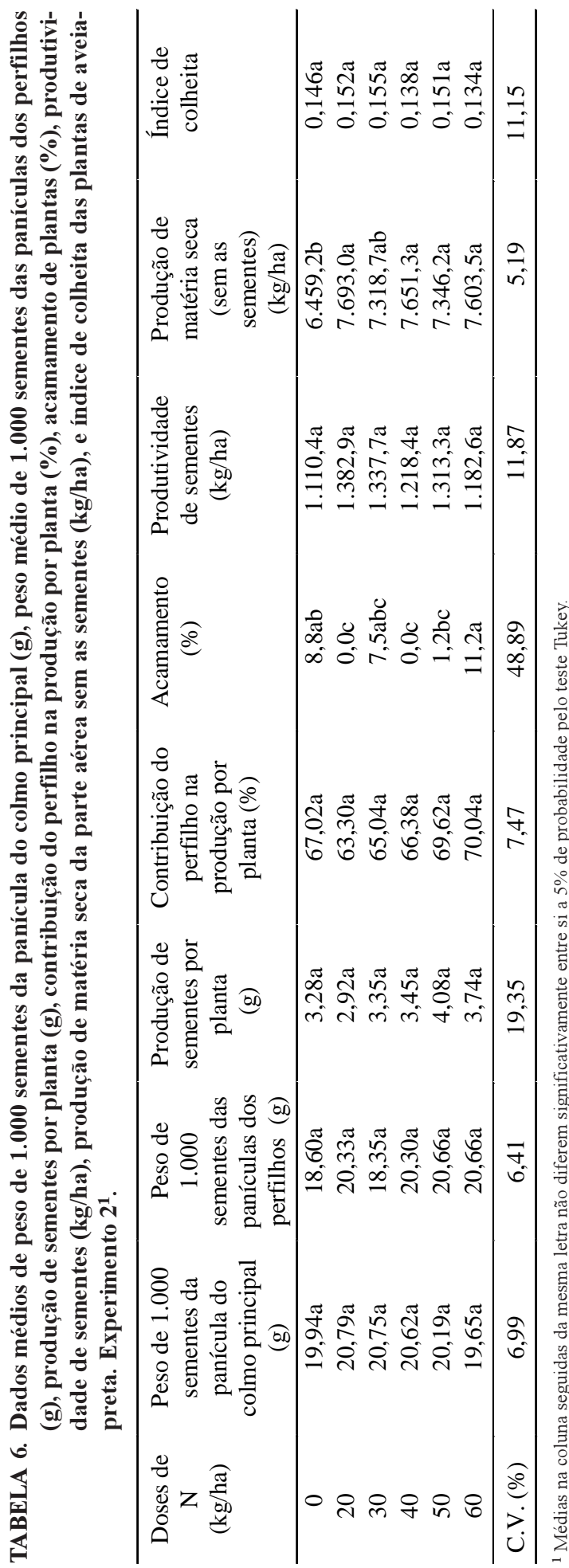

A produtividade de sementes foi semelhante, estatisticamente, em todos os tratamentos, mas verificou-se que os menores valores foram obtidos na testemunha e com a maior dose de $\mathrm{N}$ (Tabela 6). Com relação à produção da matéria seca da parte aérea, sem as sementes (Tabela 6), a testemunha foi inferior aos tratamentos que receberam adubação nitrogenada, e não houve diferença entre doses. Esses resultados diferem dos obtidos no experimento 1 (Tabela 3), em que não se constatou efeito do $\mathrm{N}$ em solo de melhor fertilidade. Nakagawa et al. (1995), entretanto, obtiveram aumentos significativos na produção de matéria seca com aumentos das doses de $\mathrm{N}$ (de 0 a $40 \mathrm{~kg} / \mathrm{ha}$ de $\mathrm{N}$ ) e na produtividade de sementes ( 0 a $20 \mathrm{~kg} / \mathrm{ha}$ de $\mathrm{N}$ ) quando essas doses foram aplicadas no perfilhamento, em solo de baixa fertilidade. O índice de colheita mostrou-se semelhante entre os tratamentos (Tabela 6) como na produção de sementes.

O teor de proteína das sementes mostrou clara tendência de elevar-se com os aumentos das doses de N, e obteve-se diferença estatística entre a testemunha e a maior dose (Tabela 7). No experimento 1 , provavelmente por ter sido conduzido em solo de melhor fertilidade, não se obteve esta discriminação estatística, embora possa notar-se a mesma tendência (Tabela 4)

O peso hectolítrico das sementes e o peso de 1.000 sementes não foram afetados pelos tratamentos. A pureza física, entretanto, foi menor nas doses maiores de $\mathrm{N}$ em comparação com a testemunha (Tabela 7). Como as impurezas predominantes eram sementes chochas, nas maiores doses, certamente, houve um aumento no número de espiguetas que não chegaram a se desenvolver em sementes.

Ao determinar-se a qualidade fisiológica das sementes, verificou-se que não foram acusadas diferenças estatísticas entre os tratamentos quanto à germinação e ao vigor, avaliado por diferentes testes (Tabela 7). Contudo, observa-se que a testemunha apresentou o menor valor numérico de germinação e o maior de condutividade elétrica, um indicativo da menor qualidade dessas sementes.

Fazendo-se uma avaliação generalizada de todos os tratamentos, pode-se observar que, de todas as características avaliadas da planta, dos componentes de produção, da produção de matéria seca da 


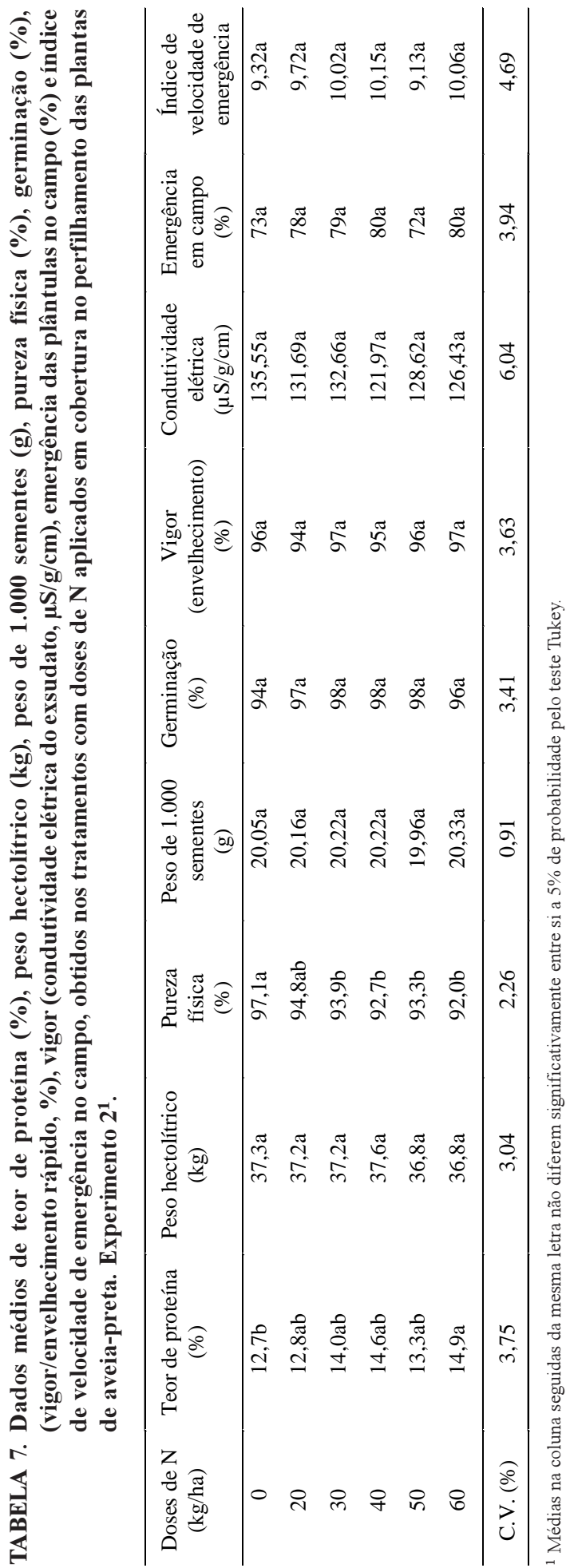

parte aérea, da produção de sementes e das características de qualidade das sementes, os valores foram sempre maiores no experimento 1 , conduzido em melhores condições de fertilidade do solo, que, entretanto, apresentou maior acamamento de plantas.

\section{CONCLUSÕES}

1. O nitrogênio aplicado em cobertura, ao final do perfilhamento das plantas de aveia-preta, em solo de maior fertilidade, provoca, na dose de $60 \mathrm{~kg} / \mathrm{ha}$, aumento do acamamento das plantas e diminuição do peso hectolítrico das sementes, e na dose de $40 \mathrm{~kg} / \mathrm{ha}$, melhoria no vigor das sementes.

2. O nitrogênio aplicado em cobertura, ao final do perfilhamento das plantas de aveia-preta, em solo de menor fertilidade, ocasiona incremento na produção de matéria seca vegetativa da parte aérea e, na dose de $60 \mathrm{~kg} / \mathrm{ha}$, aumento no teor de proteína das sementes.

\section{REFERÊNCIAS}

ASSOCIATION OF OFFICIAL ANALYTICAL CHEMISTS (Gaithersburg, Estados Unidos). Official methods of analysis. 12.ed. Washington, 1975. $1094 \mathrm{p}$.

BABA, I.; IWATA, I. Inorganic nutrition. In: MATSUBAYASHI, M.; NOMOTO, T.; ITO, R.; TAKASE, I.; YAMADA, N. (Ed.). Theory and practice of growing rice. Tokyo : Fuji, 1967. p.117139.

BRASIL. Ministério da Agricultura e Reforma Agrária. Departamento Nacional de Defesa Vegetal. Coordenação de Laboratório Vegetal. Regras para análise de sementes. Brasília, 1992. 365p.

BRINKMAN, M.A.; RHO, Y.D. Response of three oat cultivars to $\mathrm{N}$ fertilizer. Crop Science, Madison, v.24, p.973-977, 1984.

BROWN,A.R.; MORRIS, H.D.; MOREY,D.D. Response of seven oat varieties to different levels of fertilization. Agronomy Journal, Madison, v.53, p.366-369, 1961.

CARVALHO, N.M.; NAKAGAWA, J. (Coord.). Sementes: ciência, tecnologia e produção. 3.ed. rev. Campinas : Fundação Cargill, 1988. 424p.

Pesq. agropec. bras., Brasília, v.35, n.6, p.1071-1080, jun. 2000 
CARVALHO, W.A.; ESPÍNDOLA, C.R.; PACCOLA A.A. Levantamento de solos da Fazenda Lageado. Botucatu : UNESP-Faculdade de Ciências Agronômicas, 1983. 95p. (Boletim Técnico, 1)

COSTA, N.P.; GOMES, A.S.; PESKE, S.T.; POPINIGIS, F.; ZONTA, E.P. Influência da adubação nitrogenada sobre o vigor e conteúdo de proteína de sementes de quatro cultivares de arroz irrigado. Revista Brasileira de Sementes, Brasília, v.5, n.1, p.31-41, 1983.

DERPSCH, R.; SIDIRAS, N.; HEINZMANN, F.Z. Manejo do solo em coberturas verde de inverno. Pesquisa Agropecuária Brasileira, Brasília, v.20, n.7, p.761-773, jul. 1985.

FONTANELI, R.S.; PIOVEZAN, A.J. Efeitos de cortes no rendimento de forragem e grãos de aveia. Pesquisa Agropecuária Brasileira, Brasília, v.26, n.5 p.691-697, maio 1991.

FREY, K.J. Yield components in oats. II. Effects of nitrogen fertilization. Agronomy Journal, Madison, v.51, p.605-608, 1959.

GODOY, R.; BATISTA, L.A.R. Avaliação do potencial de produção de grãos de germoplasma de aveia forrageira na região de São Carlos, SP. Pesquisa Agropecuária Brasileira, Brasília, v.27, n.9, p.1253-1257, 1992.

HUMPHREYS, D.G.; SMITH, D.L.; MATHER, D.F. Nitrogen fertilizer application and seeding date effects on oat grain milling quality. Agronomy Journal, Madison, v.86, n.5, p.838-843, 1994.

INSTITUTO AGRONÔMICO (Campinas, SP). Instrucões agrícolas para o Estado de São Paulo. 3.ed rev. atual., Campinas, 1986. 229p. (Boletim, 200).

MAEDA, J.A.; SAWAZAKI, E.; POMMER, C.V. Influência de adubação mineral NPK sobre a qualidade de sementes de milho. Bragantia, Campinas, v.38, p.165-174, 1979.

MARSHALL, K.G.; KOLB, F.L.; ROTH, G.W. Effects of nitrogen fertilizer rate seedling rate and row spacing on semi-dwarf and conventional height spring oat Crop Science, Madison, v.27, p.572-575, 1987

NAKAGAWA, J.; CAVARIANI, C.; AMARAL, W.A.N.; MACHADO, J.R. Produção e qualidade de sementes de aveia-preta (Avena strigosa Schreb) em função da adubação nitrogenada. Revista Brasileira de Sementes, Brasília, v.16, n.1, p.95-101, 1994.

NAKAGAWA, J.; CAVARIANI, C.; MACHADO, J.R Efeito da dose e da época de aplicação de N na pro- dução e qualidade de sementes de aveia-preta Científica, São Paulo, v.23, n.1, p.31-43, 1995

NAKAGAWA, J.; CAVARIANI, C.; MACHADO, J.R Efeito de doses de nitrogênio aplicadas na emergência da panícula sobre a produção e qualidade de sementes de aveia-preta. Revista Brasileira de Sementes, Brasília, v.18, n.2, p.160-166, 1996.

OHM, H.W. Response of 21 oat cultivars to nitrogen fertilization. Agronomy Journal, Madison, v.58, p.773-775, 1976.

PIMENTEL-GOMES, F. Curso de Estatística experimental. Piracicaba : ESALQ, 1966. 404p.

RATTUNDE, H.F.; FREY, K.J. Nitrogen harvest index in oats, its repeatability and association with adaptation. Crop Science, Madison, v.26, p.606610,1986

REIS, R.A.; RODRIGUES, L.R. de A.; COAN, O.; RESENDE, K.T. de. Efeitos de diferentes épocas de colheita sobre a produção de forragem e de sementes de aveia-preta. Pesquisa Agropecuária Brasileira, Brasília, v.27, n.1, p.111-117, jan. 1992

SALERNO, A.R.; VETTERLE, C.P. Avaliação de forrageiras de inverno no Baixo Vale do Itajaí, Santa Catarina. Florianópolis : EMPASC, 1984. 2p. (Comunicado Técnico, 76)

SANTOS, H.P. dos. Efeitos de sistemas de cultivo sobre rendimento de grãos e outras características agronômicas da aveia-preta e da aveia-branca, em rotação com trigo. Pesquisa Agropecuária Brasileira, Brasília, v.26, n.5, p.709-714, maio 1991.

TRANI, P.E.; BULISANI, E.A.; BRAGA, N.R. Adubação verde. Campinas : Coordenadoria de Assistência Técnica Integral, 1989. 13p. (Boletim Técnico, 197).

VIEIRA, R.D.; FORNASIERI FILHO, D.; MINOHARA, L.; BERGAMASCHI, M.C.M. Efeito de doses e de épocas de aplicação de nitrogênio em cobertura na produção e na qualidade fisiológica de sementes de trigo. Científica, São Paulo, v.23, n.2, p.257-264, 1995

VIEIRA, R.D.; FORNASIERI FILHO, D.; SCHIAVON JUNIOR, A.A.; MALHEIROS, E.B. Efeitos de fontes e doses de enxofre sobre os teores de nitrogênio e enxofre e qualidade fisiológica de sementes de trigo. Revista Brasileira de Sementes, Brasília, v.8, n.2, p.45-53, 1986 